\title{
Effect of Steel Fibers on the Behavior of Over-Reinforced Beams Subjected to Pure Torsion
}

\author{
Gunneswara Rao, T.D. ${ }^{1)}$, Rama Seshu, D. ${ }^{1)}$ and Warnitchai, P.2)
}

\begin{abstract}
The improvement in torsional properties of reinforced concrete (RC) is becoming extremely important in the modern day constructions. Over the years the steel fiber reinforced concrete (SFRC) is being used for improving cracking characteristics of RC. The present paper deals with the behaviour of over reinforced SFRC members subjected to pure torsional loading. Torsion tests on the 15 reinforced steel fiber reinforced concrete beams revealed that, fiber has noticeable effect on the cracking torque and very little effect on the ultimate torsional strength of the member. However fiber inclusion could improve the torsional toughness of the member.
\end{abstract}

Keywords: Torsional strength, steel fibers, toughness, cracking torque, over reinforced members.

\section{Introduction}

Steel fiber reinforced concrete (SFRC) members occupied a place in the construction field due to their inherent capability of resisting the blast loads or dynamic loads, absorbing considerable energy. Fibers present in the concrete arrest the cracks or retard the crack propagation, which improves the tensile strength and energy absorbing property of the basic material (concrete). References [1-7] reported the effectiveness of the fibers in plain SFRC members resisting the torsional loads. In the case of reinforced concrete members subjected to pure torsional loads, both longitudinal reinforcement and transverse reinforcement along with concrete present between the potential spiral cracks share the torsional load beyond first crack [8]. The yielding of the longitudinal reinforcement or transverse reinforcement or crushing of the concrete or with their combination initiates the ultimate failure of reinforced concrete member under torsion. Thus reinforced sections subjected to pure torsional loads were categorized into five groups as detailed in Table.1.

Gunneswara Rao and Rama Seshu [7], proposed an analytical model to determine the torque twist response of steel fiber reinforced concrete members subjected to pure torsion. Gunneswara Rao [9] proposed semi-empirical formulae in SI units for determining the balanced percentages for longitudinal reinforcement and web reinforcement.

1) Department of Civil Engineering, National Institute of Technology, Warangal - 506 004, India.

Email: tdgtdg@gmail.com

2) School of Engineering and Technology, Asian Institute of Technology, Thailand

Note: Discussion is expected before June, 1st 2010, and will be published in the "Civil Engineering Dimension" volume 12, number 2, September 2010.

Received 1 March 2009; revised 30 July 2009; accepted 17 December 2009.

$$
\begin{aligned}
& a_{l b}=0.2687 b d \frac{f_{c}^{\prime}}{f_{y}} e^{-0.0021 f_{y}} \\
& a_{t b}=0.2447 \frac{b d s}{p_{h}} \frac{f_{c}^{\prime}}{f_{y}} e^{-0.0019 f_{y}} \\
& \rho_{l b}=\frac{a_{l b}}{b d} * 100 \\
& \rho_{t b}=\frac{a_{t b}}{b d}\left(\frac{p_{h}}{s}\right) * 100
\end{aligned}
$$

in which,

$a_{l b}=$ Balanced longitudinal reinforcement

$a_{t b}=$ Balanced transverse reinforcement

$a_{c}=$ Area of concrete $\left(b^{*} \mathrm{~d}\right)$

$b=$ Breadth (smaller dimension) of the cross section

$d=$ Depth (larger dimension) of the cross section

$s \quad=$ Spacing of the web reinforcement

$p_{h}=$ Perimeter of the web centre line of the stirrup

$\rho_{l b}=$ Percentage of balanced longitudinal reinforcement

$\rho_{t b}=$ Percentage of balanced transverse reinforcement

$f_{c}{ }^{\prime}=$ Cylinder compressive strength of concrete

$f_{y}=$ Average yield strength of the longitudinal and transverse reinforcement $(\mathrm{MPa})$

$f_{y l}=$ Yield strength of the longitudinal reinforcement

$f_{y t}=$ Yield strength of the web/transverse reinforcement.

In the present day modern constructions the use of slender RC sections is increasing day by day due to architectural requirement. Such slender RC sections become over reinforced at very low percentages of steel reinforcement and thus limit the useful capacities of the section under service loads. However the sections with higher percentages of 
reinforcement can be effectively used if the behavior in the range of service loads is improved. From this point of view the use of SFRC comes as an alternative. In the present investigation an attempt has been made to study the effect of steel fibers in the over reinforced category of beams, viz., beams over reinforced with respect to longitudinal reinforcement, beams over reinforced with respect to transverse reinforcement and beam over reinforced with respect to both reinforcements, subjected to pure torsion.

Table 1. Categories of RC sections under torsional loads

\begin{tabular}{|c|c|c|c|}
\hline $\begin{array}{c}\text { State of the cross } \\
\text { section }\end{array}$ & $\begin{array}{l}\text { Longitu- } \\
\text { dinal } \\
\text { reinfor- } \\
\text { cement }\end{array}$ & $\begin{array}{l}\text { Trans- } \\
\text { verse } \\
\text { reinfor- } \\
\text { cement }\end{array}$ & $\begin{array}{c}\text { Concrete } \\
\text { present } \\
\text { between } \\
\text { spiral } \\
\text { cracks }\end{array}$ \\
\hline Balanced section & Yields & Yields & Crushes \\
\hline $\begin{array}{l}\text { Over reinforced with } \\
\text { respect to longitudinal } \\
\text { reinforcement }\end{array}$ & $\begin{array}{l}\text { Doesn't } \\
\text { yield }\end{array}$ & Yields & Crushes \\
\hline $\begin{array}{l}\text { Over reinforced with } \\
\text { respect to transverse } \\
\text { reinforcement }\end{array}$ & Yields & $\begin{array}{l}\text { Doesn't } \\
\text { yield }\end{array}$ & Crushes \\
\hline $\begin{array}{l}\text { Completely over } \\
\text { reinforced }\end{array}$ & $\begin{array}{l}\text { Doesn't } \\
\text { yield }\end{array}$ & $\begin{array}{l}\text { Doesn't } \\
\text { yield }\end{array}$ & Crushes \\
\hline $\begin{array}{l}\text { Under reinforced } \\
\text { section }\end{array}$ & Yields & Yields & $\begin{array}{l}\text { Doesn't } \\
\text { Crush }\end{array}$ \\
\hline
\end{tabular}

\section{Methodology}

The experimental investigation consisted of casting and testing 15 steel fiber reinforced concrete beams under pure torsional loading. The size of each beam was $100 \mathrm{~mm}$ × $200 \mathrm{~mm}$ x $2000 \mathrm{~mm}$. The variables include the over reinforced state of the cross section and volume fraction of the fiber. The volume fraction of the fiber content varied at regular intervals of $0.3 \%$ from $0 \%$ to $1.2 \%$. The reinforcement in the beams was provided in such a way that desired over reinforced state prevails. The cases of over reinforcement considered were a) with respect to longitudinal reinforcement b) with respect to web reinforcement and c) completely over reinforced state. To determine the required quantities of longitudinal steel and web steel for arriving at different over reinforced states, the semi-empirical formulae mentioned above (Eqs. 1-4) were used. The percentage of reinforcement provided in different beams, in excess of that required for a balanced failure under torsional loads is given in Table. 2. For each category of over reinforced state five specimens with varied fiber content were tested under pure torsion.
The proportioning of concrete was maintained constant throughout the investigation. A concrete mix targeting a compressive strength of $50 \mathrm{MPa}$ was used. Figure 1 shows the cross sectional details of the beam. An effective cover of $15 \mathrm{~mm}$ is provided for the transverse reinforcement.

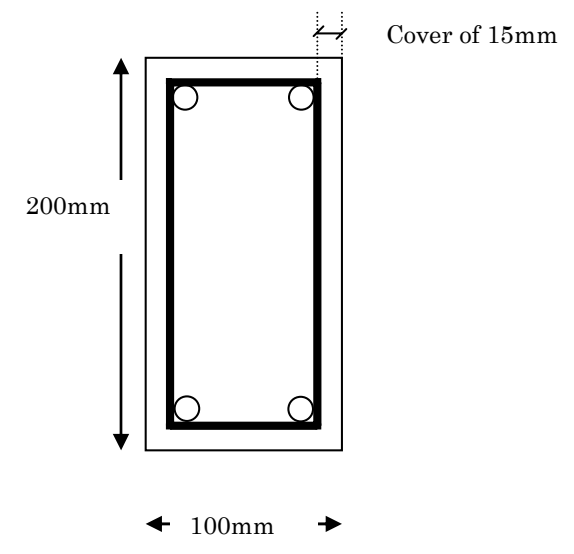

Figure 1. Cross sectional details of the beam

Table 2. Percentage of reinforcement provided in the test beams for different failure states (R50C, R50L, and R50T)

\begin{tabular}{lcc}
\hline & \multicolumn{2}{c}{ Reinforcement provided } \\
\cline { 2 - 3 } & $\begin{array}{c}\text { Longitudinal } \\
\text { reinforcement }\end{array}$ & $\begin{array}{c}\text { Transverse } \\
\text { reinforcement }\end{array}$ \\
\hline $\begin{array}{l}\text { Reinforcement } \\
\text { required for balanced } \\
\text { failure }\end{array}$ & $0.945 \%$ & $0.996 \%$ \\
$\begin{array}{l}\text { Completely over } \\
\text { reinforced failure } \\
\text { (R50C) }\end{array}$ & $1.570 \%$ & $1.506 \%$ \\
$\begin{array}{l}\text { Longitudinally over } \\
\text { reinforced failure } \\
\text { (R50L) }\end{array}$ & $(0.625 \%$ Excess) & $(0.510 \%$ Excess) \\
$\begin{array}{l}\text { Transversely over } \\
\text { reinforced failure } \\
\text { (R50T) }\end{array}$ & $1.570 \%$ & $0.803 \%$ \\
\hline & $0.565 \%$ & $(0.193 \%$ Less) \\
& & $1.506 \%$ \\
\hline
\end{tabular}

\section{Materials}

The materials used in this investigation are detailed in Table 3, while the details of the mix design, reinforcement arrangement and volume fraction of fiber added to the different elements are tabulated in Table 4. The cement content and fly ash contents were $415 \mathrm{~kg}$ and $83 \mathrm{~kg}$ per cubic meter of concrete respectively. Fine aggregate, coarse aggregate and water used for concreting are $759 \mathrm{~kg}, 880 \mathrm{~kg}$, and 190 littres per cubic meter of concrete respectively. The compressive strength as well as the split tensile strength of the mixes was also reported in Table 4. 


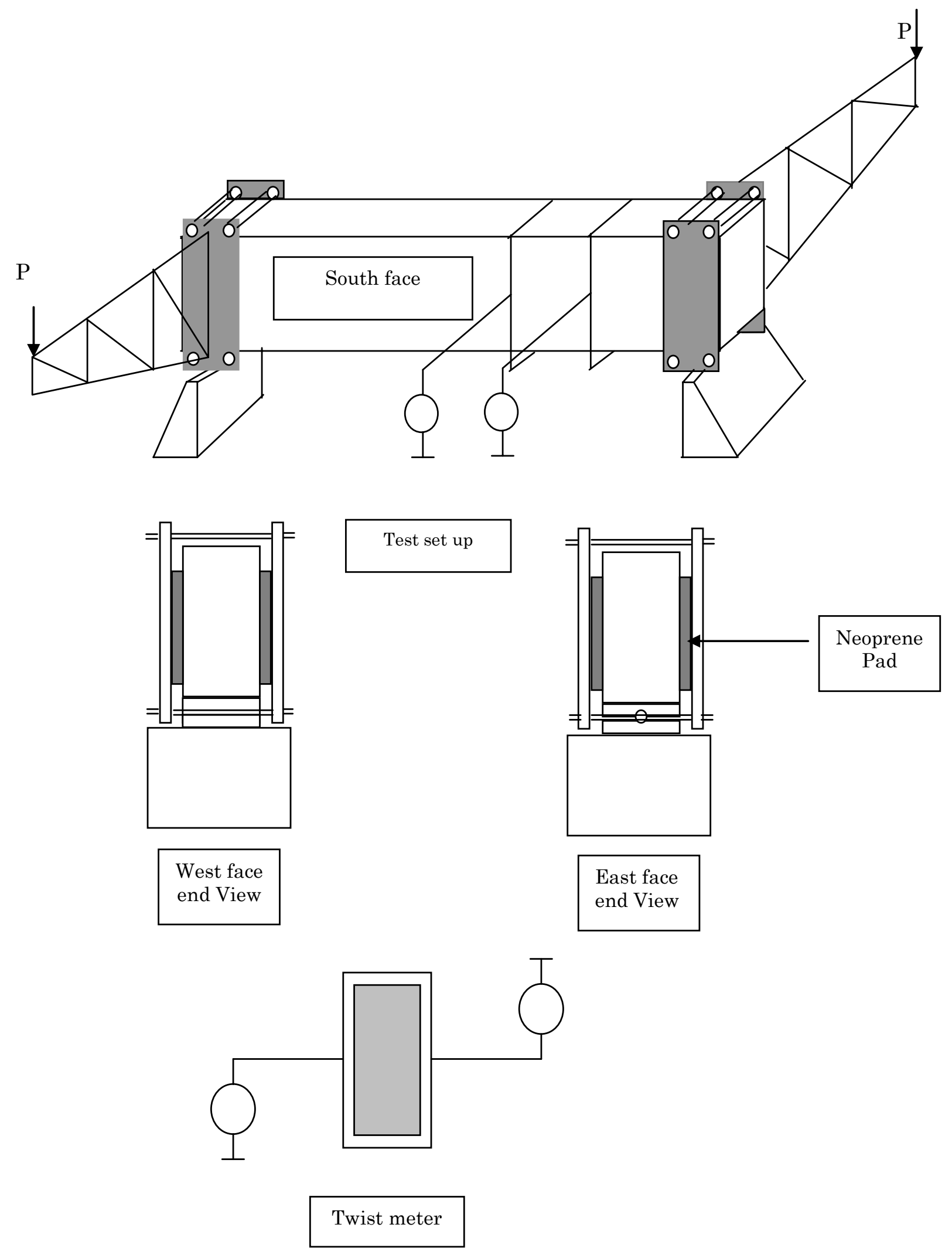

Figure 2. Overall test set up with different views 
Table 3. Characteristics of the materials used.

\begin{tabular}{ll}
\hline Material & Characteristics \\
\hline Fement & $\begin{array}{l}\text { Ordinary Portland cement of } \\
\text { compressive strength 53 MPa. } \\
\text { Confirming to the requirements of } \\
\text { ASTM-33C }\end{array}$ \\
Coarse Aggregate & $\begin{array}{l}\text { Crushed granite aggregates of } \\
\text { maximum size 12 mm }\end{array}$ \\
Water & Potable water \\
Reinforcement & $\begin{array}{l}\text { Bars of diameters 6mm, 8 mm and } \\
10 \text { mm having yield strength 432 } \\
\text { MPa were used. }\end{array}$ \\
& $\begin{array}{l}\text { 41 mm long Galvanized Iron wires } \\
\text { of diameter 0.546 mm was used. } \\
\text { Wiber }\end{array}$ \\
& $\begin{array}{l}\text { Wire is plain and straight. Wire } \\
\text { the wire is 295 MPa. }\end{array}$ \\
\hline
\end{tabular}

\section{Designation of the beams}

Each and every beam is designated by the over reinforced state viz., R50C for completely over reinforced state, R50L for longitudinally over reinforced state and R50T for transversely over reinforced state. The last letters of the designation of the beams represent the percentage volume fraction of the fiber i.e., "P" for 0, F1 for 0.3, F2 for 0.6, F3 for 0.9 and $\mathrm{F} 4$ for 1.2 percentage of volume fraction of fiber content.

\section{Casting and testing of beams}

Rigid mild steel channel moulds were arranged on a smooth horizontal rigid level platform for casting the beams. The required quantities of the materials for casting one beam and the companion cylinders were mixed in an electrically operated mixer. The fibers were added to the mixer manually in small quantities intermittently to avoid balling of fibers. The time necessary for complete concreting was well within the initial setting time of the cement. The beams and cylinders were removed from the moulds carefully after 24 hours of casting and were fed to the curing tank. The cured beams were white washed a day before testing to facilitate the crack angle identification and measurement. The test beam was mounted on the wing table of the testing machine. One end of the beam was supported on rollers, while the other end was supported on rigid support. This type of test setup facilitates free rotation of roller end and provides stability to the test specimen during testing. Specially made twist arms are placed at both supports of the beam having an arm length of $1.5 \mathrm{~m}$. Load on the twist arm was applied through a mechanical screw jack and the loading was monitored through a proving ring attached to the jack. Absolute care has been taken, such that, the plane of loading and twisting arm were perpendicular to the longitudinal axis of the beam. This avoids any possibility of bending of the beam instead of twisting and as a result the beam between the two supports was subjected to pure torsion. The complete test setup is schematically presented in Figure 2. Figure 3 shows the actual test set up. Load was applied at an eccentricity of $1.47 \mathrm{~m}$ from the center of the beam. At the restraining end a proving ring was placed to verify the reaction torque. For every increment of load, the corresponding dial gauge readings of the twist meter were noted for computing twist per unit length

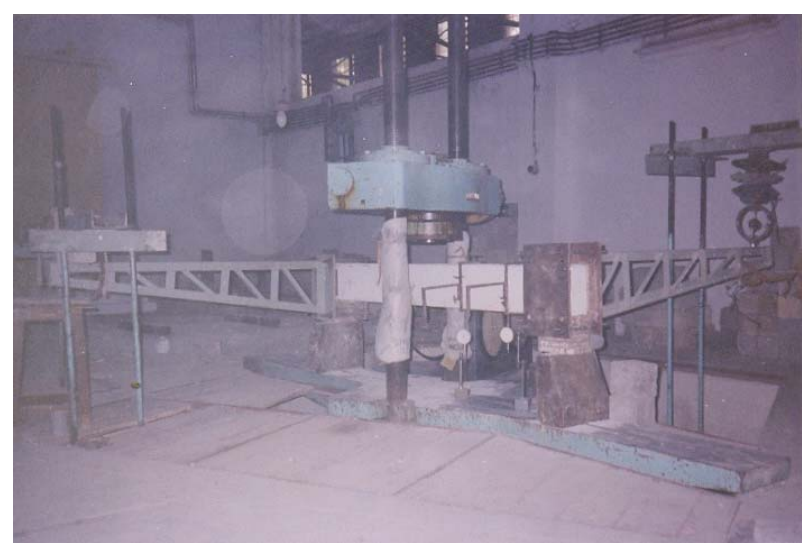

Figure 3- Test set up

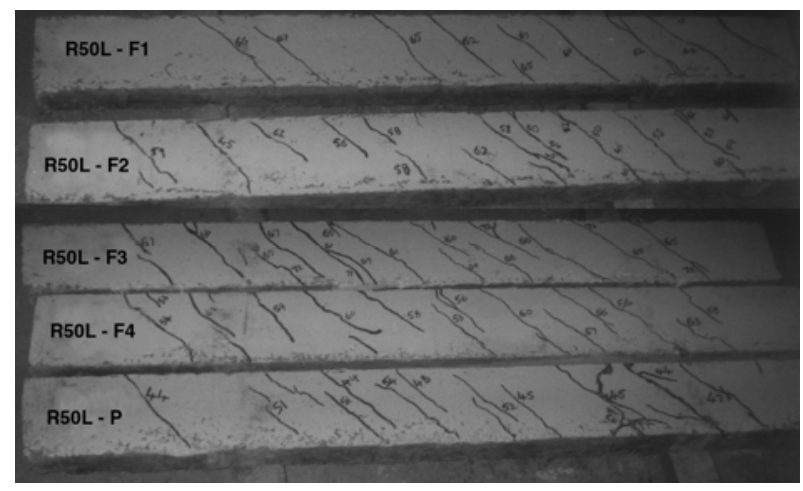

Figure 4. Tested longitudinally over reinforced beams

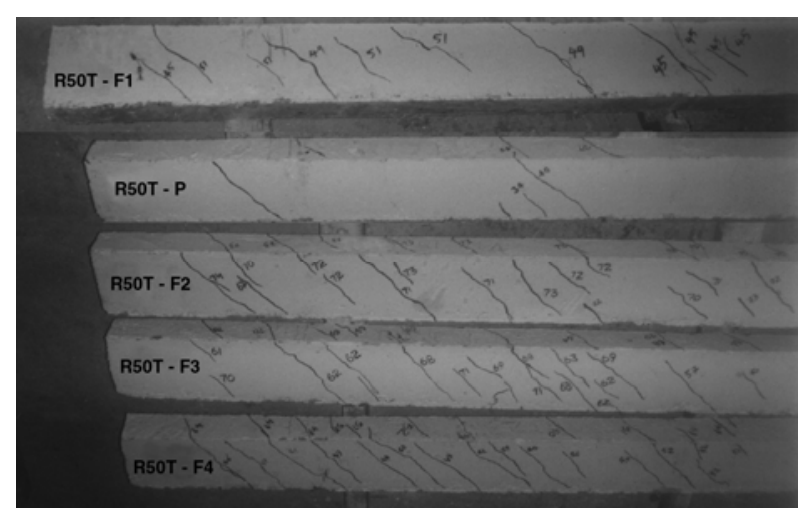

Figure 5 . Tested transversely over reinforced beams 
Table 4. Concrete mix details and reinforcement details of the tested beams.

\begin{tabular}{|c|c|c|c|c|c|c|}
\hline \multirow{2}{*}{$\begin{array}{l}\text { Designation } \\
\text { of the beam }\end{array}$} & \multicolumn{2}{|c|}{$\begin{array}{l}\text { Mix details kg per } \\
\text { cubic meter of } \\
\text { concrete }\end{array}$} & \multirow{2}{*}{$\begin{array}{l}\text { Longitudinal } \\
\text { reinforcement }\end{array}$} & \multirow{2}{*}{$\begin{array}{l}\text { Uniform spacing of } \\
\text { transverse } \\
\text { reinforcement of two } \\
\text { legged 8mm dia. bars }\end{array}$} & \multirow{2}{*}{$\begin{array}{c}\text { Cylinder } \\
\text { compressive } \\
\text { strength in } \\
\text { MPa }\end{array}$} & \multirow{2}{*}{$\begin{array}{c}\text { Split } \\
\text { tensile } \\
\text { strength in } \\
\text { MPa }\end{array}$} \\
\hline & $\begin{array}{c}\text { Super } \\
\text { plasticizer }\end{array}$ & $\begin{array}{l}\text { Steel } \\
\text { fibers }\end{array}$ & & & & \\
\hline R50C-P & 0 & 0 & 4\# $10 \mathrm{~mm}$ dia. bars & $80 \mathrm{~mm} \mathrm{c} / \mathrm{c}$ & 50.12 & 2.90 \\
\hline R50C -F1 & $400 \mathrm{ml}$ & 23.55 & 4\# $10 \mathrm{~mm}$ dia. bars & $80 \mathrm{~mm} \mathrm{c/c}$ & 50.95 & 3.11 \\
\hline R50C -F2 & $500 \mathrm{ml}$ & 47.10 & 4\# $10 \mathrm{~mm}$ dia. bars & $80 \mathrm{~mm} \mathrm{c} / \mathrm{c}$ & 51.82 & 3.36 \\
\hline R50C -F3 & $650 \mathrm{ml}$ & 70.65 & 4\# $10 \mathrm{~mm}$ dia. bars & $80 \mathrm{~mm} \mathrm{c} / \mathrm{c}$ & 52.45 & 3.88 \\
\hline $\mathrm{R} 50 \mathrm{C}-\mathrm{F} 4$ & $800 \mathrm{ml}$ & 94.20 & 4\# $10 \mathrm{~mm}$ dia. bars & $80 \mathrm{~mm} \mathrm{c} / \mathrm{c}$ & 53.90 & 4.38 \\
\hline R50L-P & 0 & 0 & 4\# $10 \mathrm{~mm}$ dia. bars & $150 \mathrm{~mm} \mathrm{c} / \mathrm{c}$ & 50.21 & 2.89 \\
\hline R50L -F1 & $400 \mathrm{ml}$ & 23.55 & 4\# $10 \mathrm{~mm}$ dia. bars & $150 \mathrm{~mm} \mathrm{c} / \mathrm{c}$ & 51.05 & 3.04 \\
\hline R50L -F2 & $500 \mathrm{ml}$ & 47.10 & 4\# $10 \mathrm{~mm}$ dia. bars & $150 \mathrm{~mm} \mathrm{c} / \mathrm{c}$ & 52.06 & 3.51 \\
\hline R50L -F3 & $650 \mathrm{ml}$ & 70.65 & 4\# $10 \mathrm{~mm}$ dia. bars & $150 \mathrm{~mm} \mathrm{c} / \mathrm{c}$ & 53.41 & 3.87 \\
\hline R50L -F4 & $800 \mathrm{ml}$ & 94.20 & 4\# $10 \mathrm{~mm}$ dia. bars & $150 \mathrm{~mm} \mathrm{c} / \mathrm{c}$ & 54.07 & 4.35 \\
\hline R50T-P & 0 & 0 & 4\# 6 mm dia. bars & $80 \mathrm{~mm} \mathrm{c} / \mathrm{c}$ & 51.35 & 2.91 \\
\hline R50T -F1 & $400 \mathrm{ml}$ & 23.55 & 4 \# $6 \mathrm{~mm}$ dia. bars & $80 \mathrm{~mm} \mathrm{c} / \mathrm{c}$ & 52.64 & 3.29 \\
\hline R50T -F2 & $500 \mathrm{ml}$ & 47.10 & 4 \# $6 \mathrm{~mm}$ dia. bars & $80 \mathrm{~mm} \mathrm{c} / \mathrm{c}$ & 53.15 & 3.71 \\
\hline R50T -F3 & $650 \mathrm{ml}$ & 70.65 & 4 \# $6 \mathrm{~mm}$ dia. bars & $80 \mathrm{~mm} \mathrm{c} / \mathrm{c}$ & 54.12 & 4.05 \\
\hline R50T -F4 & $800 \mathrm{ml}$ & 94.20 & 4 \# 6 mm dia. bars & $80 \mathrm{~mm} \mathrm{c} / \mathrm{c}$ & 55.51 & 4.45 \\
\hline
\end{tabular}

Table 5. Test results of SFRC beams under pure torsion

\begin{tabular}{lccccccc}
\hline $\begin{array}{c}\text { Beam } \\
\text { designation }\end{array}$ & $\begin{array}{c}\text { Cracking } \\
\text { torque } \\
\mathbf{k N m}\end{array}$ & $\begin{array}{c}\text { Angle of twist at } \\
\text { cracking } \\
\text { torque } \\
\text { rad/m }\end{array}$ & $\begin{array}{c}\text { Ultimate } \\
\text { torque } \\
\mathbf{k N m}\end{array}$ & $\begin{array}{c}\text { Ultimate } \\
\text { twist } \\
\text { rad/m }\end{array}$ & $\begin{array}{c}\text { Torsional } \\
\text { toughness } \\
\mathbf{k N m}\end{array}$ & $\begin{array}{c}\text { Initial } \\
\text { stiffness } \\
\mathbf{k N m}^{2}\end{array}$ & $\begin{array}{c}\text { Post cracking } \\
\text { torsional } \\
\text { stiffness kNm }^{2}\end{array}$ \\
\hline R50C-P & 2.057 & 0.039 & 6.584 & 0.138 & 0.624 & 641.287 & 62.128 \\
R50C -F1 & 2.199 & 0.047 & 6.670 & 0.141 & 0.638 & 666.938 & 58.495 \\
R50C -F2 & 2.367 & 0.052 & 6.755 & 0.141 & 0.662 & 679.764 & 57.609 \\
R50C -F3 & 2.710 & 0.057 & 6.841 & 0.141 & 0.681 & 692.589 & 58.785 \\
R50C -F4 & 3.039 & 0.060 & 6.926 & 0.141 & 0.695 & 705.345 & 58.785 \\
R50L-P & 2.050 & 0.039 & 5.131 & 0.173 & 0.700 & 615.635 & 44.386 \\
R50L -F1 & 2.152 & 0.049 & 5.216 & 0.173 & 0.706 & 654.112 & 45.863 \\
R50L -F2 & 2.467 & 0.058 & 5.302 & 0.176 & 0.736 & 657.319 & 47.791 \\
R50L -F3 & 2.707 & 0.063 & 5.387 & 0.179 & 0.761 & 673.351 & 48.784 \\
R50L -F4 & 3.020 & 0.068 & 5.473 & 0.180 & 0.788 & 694.727 & 53.078 \\
R50T-P & 2.066 & 0.034 & 5.687 & 0.156 & 0.659 & 676.557 & 54.163 \\
R50T -F1 & 2.323 & 0.045 & 5.772 & 0.156 & 0.672 & 692.589 & 54.163 \\
R50T -F2 & 2.602 & 0.043 & 5.815 & 0.163 & 0.722 & 705.415 & 50.285 \\
R50T -F3 & 2.827 & 0.053 & 5.900 & 0.163 & 0.736 & 716.103 & 53.339 \\
R50T -F4 & 3.090 & 0.061 & 5.986 & 0.167 & 0.786 & 731.067 & 54.414 \\
\hline
\end{tabular}

Table 6. Relative improvement in different torsional properties of reinforced members with the addition of fibers.

\begin{tabular}{lccccccccccc}
\hline & \multicolumn{3}{c}{ Relative improvement over conventionally reinforced concrete at different fiber } \\
volume fraction
\end{tabular}




\section{Twist measurement}

Twist meters specially prepared in the laboratory were used to measure the twist of the beam. The twist meters consist of steel frames as shown in Figure 1 and can be attached to the beam by means of transverse screws. The steel frames were welded with steel arms of length $200 \mathrm{~mm}$ on vertical sides of the frame. Dial gauges placed under the steel arms of the twist-meter allow the measurement of rotation of the cross- section of the beam. Such two frames were spaced at a gauge distance of $300 \mathrm{~mm}$. This facilitates the measurement of twist per unit length of the beam. Strains in rebars and surface concrete could not be measured as strain gauges were not installed at the time of casting.

\section{Test results and discussion}

The experimental results of all reinforced SFRC members, viz., cracking torque, twist at cracking torque, Ultimate torque, corresponding twist, pre cracking torsional stiffness, post cracking torsional stiffness and torsional toughness are presented in Table 5. Cracking torque was considered as the torque in the torque twist diagram where the curve has deviated from linearity. Torsional stiffness was calculated from the torque twist response of the concerned member. The area under the torque twist response of the member was taken as the representative of the torsional toughness of the member.

Fiber inclusion improved the cracking torque of all beams irrespective of the over reinforced state. The crack patterns of longitudinally over reinforced and transversely over reinforced beams were presented in Figure 4 and Figure 5 respectively. In Figure 4, R50L-F2 represents longitudinally over reinforced beams with fiber content of $0.6 \%$. Similarly in Figure 5, R50T-P represents transversely over reinforced beam without fiber content. The torque twist responses of the tested members were presented in Figure 6, Figure 7 and Figure 8. From the torque twist responses of the beams it is clear that there exist three distinct phases in the response of the member viz., pre-cracking phase, transition phase and post cracking phase. The torsional stiffness of the member pre cracking phase is high, as the total cross section of the beam resists the torsional load. Post cracking torsional stiffness is notably smaller compared to pre cracking torsional stiffness, because in this phase the member develops spiral cracking and core concrete does not contribute anything either for the stiffness or for the strength of the member [8]. In the post cracking phase, the reinforcement and the concrete between the spiral cracks, resists the stresses (Truss model). The transition phase is the phase during which the complete truss action activates in the member. The reduction in torsional stiffness in post cracking phase of the member depended upon the over reinforced state of the cross section. The post cracking torsional stiffness in case of longitudinally/transversely over reinforced beams was found to be less than that of the completely over reinforced members. This may be due to the activation of more reinforcement present in the completely over reinforced beam.

Smaller crack widths were noticed in SFRC beams compared to reinforced beams without fibers. Also the cracks propagated at reduced rate in SFRC beams. In SFRC beams more cracks were observed compared to conventional reinforced beam. In other words crack spacing decreased in SFRC beams. No spalling of concrete was observed during the testing. In all reinforced beams, little improvement in ultimate torsional strength was noticed with the addition of fibers. However, fibers improved the stiffness and toughness of the beam. This improvement may be due to the tension stiffening of SFRC in the post cracking stage and improved modulus of SFRC (law of mixtures as indicated by Romauldi and Mandel [10]) in the pre cracking stage.

\section{Longitudinally over reinforced beams}

The improvement in the ultimate torsional strength of beams with fiber content of $1.2 \%$ was found to be about $7 \%$ of that of reinforced concrete beam without steel fibers. The improvement in torsional toughness of SFRC beams with $1.2 \%$ volume fraction of the fiber over conventional reinforced concrete member is $13 \%$. Inclusion of fibers improved the cracking torque by $47 \%$ when the fiber volume fraction is $1.2 \%$. From these values it is clear that fibers present in SFRC beams have beneficial effect in improving the cracking torque of the beam. The crack angle measured with the longitudinal axis of the beam in this series of beams, varied from $40^{\circ}-44^{\circ}$. Inclusion of fiber improves the torsional toughness of the member noticeably, which is indicated by the increase in the area under the torque twist curve. (Figures 6-8)

\section{Transversely over reinforced beams}

The cracking torque of transversely over reinforced members was found to be $36.3 \%$ of ultimate torque in the case of non-SFRC members. The cracking torque in case of SFRC beams was found to be about $51.6 \%$ of ultimate torque when the fiber content is $1.2 \%$. The twist at cracking torque has increased with the addition of fibers. This indicates that beams can undergo more twist without cracking in presence of fibers, which improve the performance at service loads of beams under pure torsion. The percentage improvement in the torsional toughness was found to be $19 \%$ for transversely over reinforced beams with $1.2 \%$ of fiber content. The crack angle measured with the longitudinal axis of the beam in this series of beams, varied from $48^{\circ}-52^{\circ}$. 


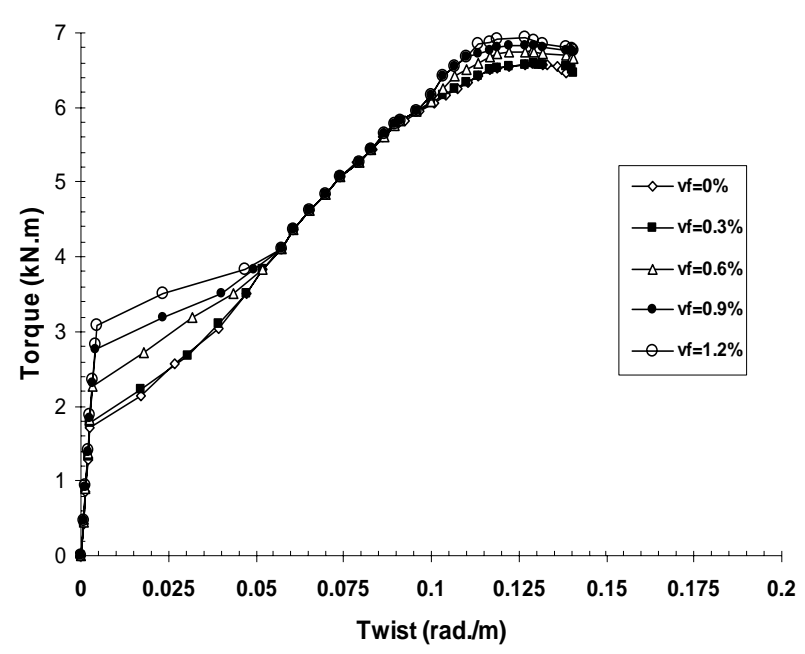

Figure 6. Torque twist response of completely over reinforced members

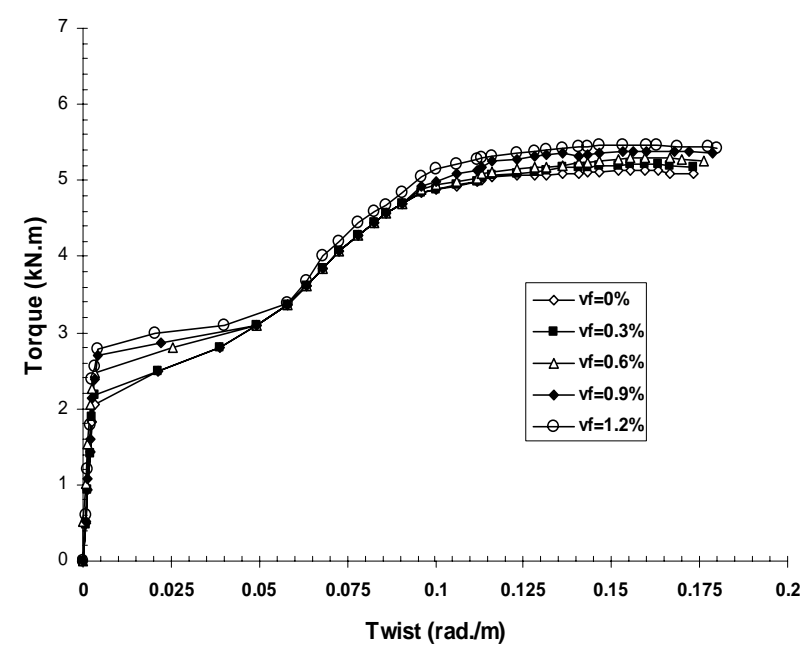

Figure7. Torque twist response of longitudinally over reinforced members

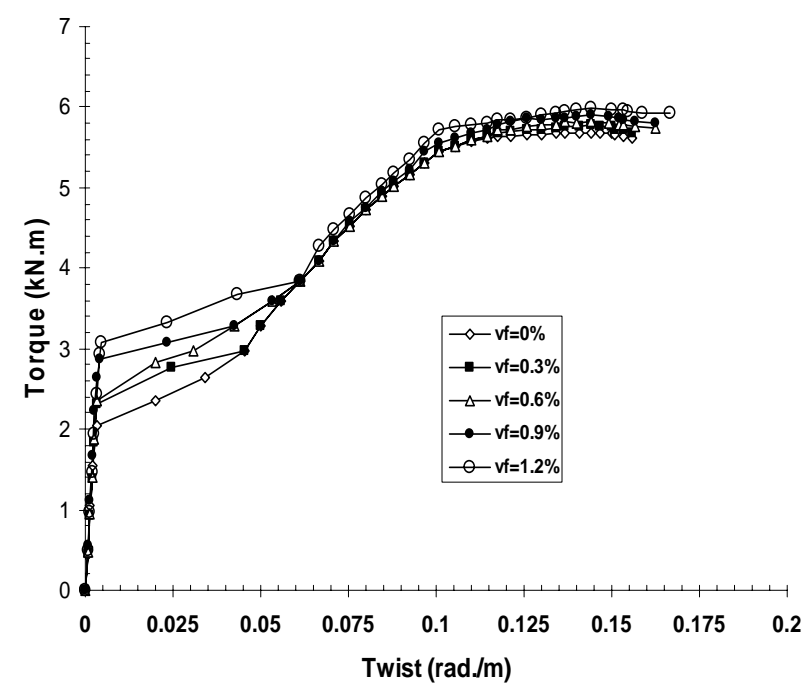

Figure 8. Torque twist response of transversely over reinforced members

\section{Completely over reinforced beams}

Fiber inclusion improved the cracking torque, torsional toughness, initial torsional stiffness and post cracking torsional stiffness of the beams. Cracking torque of non-SFRC beams was $31.2 \%$ of ultimate torque of the corresponding beam. The cracking torque of SFRC beam in this series of beams was found to be $43.88 \%$ of ultimate torque of the corresponding beam with $1.2 \%$ of volume fraction of the fiber. This clearly shows that fiber inclusion improves the cracking resistance of the member. Improvement in ultimate torque with the addition of the fibers was found to be very little. When volume fraction of fiber was $1.2 \%$, the percentage increase in torsional toughness was found to be $11 \%$ over conventionally reinforced beams. The crack angle measured with respect to longitudinal axis of the beam range from $46^{\circ}$ to $52^{\circ}$.

The relative improvement in the different torsional properties of the reinforced SFRC beams with the addition of fiber is presented in the Table 6. From this table, it is clear that fiber inclusion improves the cracking torque appreciably compared to the ultimate torque. This may be attributed to the fact that the presence of fibers improves the shear strength of the basic matrix. In the post cracking stage, the reinforcement takes the major share of the torque, thus fibers will have little influence on the ultimate torsional strength of the member. This is indicated by the very little improvement observed in ultimate torque with the addition of the fibers. In the post cracking stage, the concrete diagonal present between two consecutive cracks, longitudinal reinforcement and transverse reinforcement resists the torsional load. The concrete diagonal bends into the shape of hyperbolic paraboloid [11]. Thus concrete present in between the diagonal is subjected to compressive stress and the tensile stresses are resisted by the longitudinal and transverse reinforcement. In light of this fiber present in the matrix has to participate in resisting the compressive stress only. As fiber in concrete hardly improves the compressive strength of the matrix, no appreciable increase in the ultimate torsional strength of the members is noticed. As all the tested members are in one way or other over reinforced, thus fiber influence is not seen in the ultimate torsional strength. In the similar lines, fibers in the beam have improved twist at cracking torque considerably than the twist at the ultimate torque.

\section{Conclusions}

Based on the experimental investigation on the torsionally over reinforced beams the following conclusions have been drawn. 
1. Fiber addition was found to be more beneficial in the pre-cracking phase of the reinforced beams subjected to pure torsional loads. Fiber volume fraction of $1.2 \%$, improved the cracking torque by about $47 \%$ over conventional RC member.

2. Addition of fibers improved the torsional toughness of the beam. Fiber volume fraction of $1.2 \%$, improved the torsional toughness by about $10 \%$ over conventional RC member.

3. Fiber addition makes the members to have improved performance under torsional service loads.

4. Fiber addition has very little improvement on the ultimate torsional strength of the member irrespective of the way in which the beam is over reinforced with respect to torsional loads. Even at $1.2 \%$ fiber volume fraction, the increase in the ultimate torsional strength is noticed as 5\%.

5. Addition of fibers increased the twist at cracking torque more compared to the same at the ultimate torque.

\section{Acknowledgements}

Authors are highly thankful to the authorities of National Institute of Technology Warangal, for providing necessary materials and equipment for conducting the experimental program.

\section{References}

1. Narayanan, R. and Toorani-Goloosalar, Z., Fibre Reinforced Concrete in Pure Torsion and Combined Bending and Torsion, Proceedings of Institution of Civil Engineers Part 2, 1979, pp. 987-1001.

2. Hafeez Khan, T.A., Sanjeeva Reddy, T., and Murthy P.S., An Experimental Study of FibreReinforced Concrete Beams under Pure Torsion, Indian Concrete Journal, October 1976, pp. 314317.

3. Mansur, M. A. and Paramasivam, P., Fiber Reinforced Concrete Beams in Torsion, Bending, and Shear, ACI Journal, January-February 1985, pp. 33-39.
4. Craig, J.R., Dunya, S., Riaz, J., and Shirazi H. Torsional Behavior of Reinforced Fibrous Concrete Beams, ACI Special Publication SP 81, Paper 81-2, International Symposium on FibreReinforced Concrete, American Concrete Institute, Detroit, MI, 1984, pp. 17-49.

5. Batson, G., Terry, T., Chang, M.S., Fibre Reinforced Concrete Beams Subjected to Bending and Torsion, ACI Special Publication SP 81, Paper 81-3, International Symposium on FibreReinforced Concrete, American Concrete Institute, Detroit, MI, 1984, pp. 50-68.

6. Gunneswara Rao, T.D. and Rama Seshu, D., Torsion of steel fiber reinforced concrete members, Cement and Concrete Research, Vol.33, 2003, pp. 1783-1788.

7. Gunneswara Rao, T.D. and Rama Seshu, D., Analytical model for the torsional response of steel fiber reinforced concrete members under pure torsion, Cement Concrete and Composites, Vol. 27/4, 2005, pp. 493-501.

8. Rahal. K.N., and Collins, M.P., Simple Model for Predicting Torsional Strength of Reinforced and Prestressed Concrete Sections, ACI Structural Journal, Nov.-Dec. 1996, pp. 658-666.

9. Gunneswara Rao T.D., Effect of Inclusion of Steel Fibers on the Behaviour of Reinforced Concrete Beams under Different Torsional States, Ph.D. Thesis Submitted for Kakatiya University, Warangal, India, 2003.

10. Romauldi, J.P. and Mandel, J.A, Tensile Strength of Concrete as Effected by Uniformly Distributed and Closely spaced Short Length of Wire Reinforcement, ACI Journal, Vol.61, No.6, June 1964, pp. 127-134.

11.Hsu, T.T.C., Softened Truss Model Theory for Shear and Torsion, ACI Structural Journal, November-December 1982, pp. 624-634. 